\title{
CIÊNCIA E TV: ESTUDO SOBRE A PROGRAMAC̦ÃO DA REDE RECORD
}

RESUMO: Neste artigo, apresentamos uma análise de conteúdo da programação da TV Record, visando a examinar peças relacionadas à ciência. Nossa amostra foi formada pelo conteúdo veiculado pela emissora ao longo de duas semanas construídas, representativas de seis meses (junho a novembro de 2013). Identificamos 847 peças de ciência de distintas categorias televisivas, representando $7,0 \%$ da programação assistida. As publicidades foram a categoria televisiva mais recorrentemente associada à ciência. Materiais relacionados às Ciências Biológicas e à Medicina e Saúde foram os mais frequentes, principalmente nas publicidades. Houve reduzida presença da figura do cientista: de todo o material analisado, apenas 3,5\% exibia cientistas, em maioria estrangeira. Dos 38 pesquisadores presentes, apenas cinco eram mulheres.

Palavras-chave: Cobertura sobre ciência. Televisão. TV Record.

\section{LA CIENCIA Y LA TELE: ESTUDIO ACERCA DE LA PROGRAMACIÓN DE REDE RECORD}

RESUMEN: En este artículo, presentamos un análisis de contenido de la programación de Record TV con la intención de examinar exhibiciones relacionadas a la ciencia. Nuestra muestra se constituyó de contenido vehiculado por la emisora a lo largo de dos semanas construidas, representativas de seis meses (de junio a noviembre de 2013). Identificamos 847 exhibiciones acerca de ciencia de distintas categorías televisivas, que representaban un 7,0\% de la programación vista. Las publicidades fueron la categoría televisiva más recurrente que se asoció a la ciencia. Materiales relacionados a las Ciencias Biológicas y a la Medicina y Salud fueron los más frecuentes, principalmente en las publicidades. Hubo una presencia reducida de la figura del científico: de todo el material analizado, solamente un 3,5\% exhibía científicos, la mayoría extranjera. De los 38 investigadores presentes, sólo cinco eran mujeres.

Palabras-clave: Cobertura acerca de ciencia. Televisión. Record TV.

\author{
Vanessa Brasil de Carvalho* \\ Luisa Massarani** \\ Marina Ramalho*** \\ Luis Amorim**** \\ Maria Ataide Malcher****
}

*Doutoranda do Programa
de Educação, Difusão e Gestão em
Biociências, no Instituto
de Bioquímica Médica Leopoldo
de Meis da Universidade Federal
do Rio de Janeiro. Colaboradora do
Núcleo de Estudos da Divulgação
Científica do Museu da Vida,
da Fundação Oswaldo Cruz.
Bolsista CAPES.

Rio de Janeiro, RJ - Brasil.

Email: < vanessabrasilcarvalho@ gmail.com $>$.

${ }^{*}$ *Doutora pelo Programa de Educação, Difusão e

Gestão em Biociências, no Instituto de Bioquímica

Médica Leopoldo de Meis

da Universidade Federal

do Rio de Janeiro (2001).

É coordenadora do Programa de Pós-Graduação em Divulgação da Ciência,

Tecnologia e Saúde, da Casa

de Oswaldo Cruz, Fundação Oswaldo Cruz (Fiocruz).

Bolsista Produtividade do CNPq (nível 1C).

Rio de Janeiro, RJ - Brasil.

Email:

<luisa.massarani@fiocruz.br >

*** Doutora pelo Programa

de Educação, Difusão e Gestão em Biociências, no Instituto

de Bioquímica Médica Leopoldo

de Meis da UFRJ (2013).

É pesquisadora do Núcleo de

Estudos da Divulgação Científica

do Museu da Vida e professora

do Programa de Pós-Graduação

em Divulgação da Ciência,

Tecnologia e Saúde, ambos da

Casa de Oswaldo Cruz,

Fundação Oswaldo Cruz (Fiocruz).

Rio de Janeiro, RJ - Brasil.

Email:

<marina.fiocruz@gmail.com>. 


\section{SCIENCE AND TV: A RESEARCH ABOUT REDE RECORD'S BROADCAST}

ABSTRACT: In this paper, we present a content analysis of the content broadcast by TV Record, aiming to exam programs related to science. We have worked with a sample of two constructed weeks, representing six months (June to November 2013). We have identified 847 science programs of different TV categories, representing $7.0 \%$ of watched programming. Advertisings were the television category more recurrently associated with science in our sample. Subjects related to Life Sciences and Medicine and Health were the most frequent, especially in advertising. There was reduced presence of the figure of scientists: of the total of the material analyzed, only $3.5 \%$ showed scientists, most of them foreigners. Of the 38 scientists, only five were women.

Keywords: Coverage of science. TV. TV Record.

**** Doutorando do Programa de
Pós-Graduação em Ensino
em Biociências e Saúde, da
Fundação Oswaldo Cruz.
É coordenador do Núcleo de
Estudos da Divulgação Científica do
Museu da Vida, da Casa
de Oswaldo Cruz, Fundação
Oswaldo Cruz (Fiocruz).
Rio de Janeiro, RJ - Brasil.
Email:
<Iha2000@gmail.com>.
***Doutora e mestre em
Ciências da Comunicação
pela Universidade
de São Paulo (USP).
Professora do Programa
de Pós-Graduação Criatividade e
Inovação em Metodologias
de Ensino Superior e do
Programa de Pós-Graduação
Comunicação, Cultura e Amazônia,
ambos da Universidade Federal do
Pará (UFPA), e do Programa
de Pós-Graduação em Divulgação
da Ciência, Tecnologia e Saúde
da Casa de Oswaldo Cruz,
Fundação Oswaldo Cruz (Fiocruz).
Rio de Janeiro, RJ - Brasil.
Email:
$<$ ataidemalcher@uol.com.br >




\section{INTRODUÇÃO}

A televisão é o meio de comunicação mais influente na maior parte dos países latino-americanos, de acordo com Reimão (2000). No Brasil, está presente em 97,1\% dos domicílios (IBGE, 2016) e é uma fonte importante de informações para outras mídias, como programas de rádio, jornais impressos, filmes, livros e sites de internet. Tal fato torna a TV um estimulador de debates em âmbito nacional, de maneira que esse meio de comunicação é visto por Reimão (2000, p. 62) como o "eixo central da indústria cultural nacional".

Além disso, é uma das principais fontes de informações científicas para os brasileiros, como mostrou enquete nacional realizada pelo Ministério da Ciência, Tecnologia e Inovação e pelo Centro de Gestão e Estudos Estratégicos (2015). Resultados semelhantes são observados em países da Europa, nos Estados Unidos e na América Latina (EUROPEANCOMMISSION, 2007; NATIONAL SCIENCE FOUNDATION, 2012; OCyT, 2014; REDCYTEC, CONARE, 2012; MINCYT, 2014; CONICYT, 2016).

Para José Reis (2002, p. 76-77), a divulgação científica "é muito importante, principalmente em países como o Brasil, onde as dificuldades e as precariedades das escolas fazem com que estudantes e professores obtenham informações sobre os progressos da ciência através de artigos de jornais". Em âmbito latino-americano, García-Canclini (2008) defende que a educação formal precisa fazer uso da TV e dos computadores para se relacionar de uma forma mais estreita com os estudantes.

No Brasil, pesquisadores veem analisando diversos temas de ciência na TV. Rosa e colaboradores (2005), por exemplo, trabalharam com a imagem dos cientistas construída por crianças, a partir de desenhos animados. Mesquita e Soares (2008) também estudaram desenhos animados, ressaltando a utilização dos mesmos como materiais didáticos e evidenciando a presença desse tipo de programação na formação de crianças e jovens, como também destacaram GarcíaCanclini (2008) e Reis (2002).

Ainda em relação a programações de ficção, estudos sobre telenovelas brasileiras (MASSARANI, MOREIRA, 2002; GUERRA, 2004) mostraram a presença de questões científicas em suas narrativas, fato relevante, se levarmos em consideração que as temáticas dessa programação são discutidas na vida cotidiana do brasileiro (REIMÃO, 2000). Além disso, estudos já mostram que o público está familiarizado com alguns procedimentos e métodos científicos mostrados em seriados televisivos, como é o caso do seriado CSI: Criminal Scene Investigation (THOMAS, 2006; COLE,DIOSO-VILLA, 2009; LEY, JANKOWSKI, BREWER, 2012).

Siqueira (1998), Rondelli (2004) e Medeiros e colaboradores (2013), por sua vez, se dedicaram à análise de um dos programas de variedades mais duradouros da história da TV brasileira, o Fantástico, da Rede Globo. Segundo Medeiros e colaboradores (2013), em um período de 12 meses (abril de 2009 a março de 2010), houve em média um pouco mais de duas matérias sobre temas de ciência e tecnologia por programa.

A inserção da ciência em materiais informativos brasileiros tem sido uma área mais bem explorada por pesquisadores. Barca (2004), por exemplo, comparou os materiais relacionados a temas científicos apresentados em dois telejornais 
brasileiros e um norte-americano, mostrando que tais assuntos estavam presentes em 80,3\% das edições dos telejornais analisados, principalmente relacionados a temáticas de saúde. Alberguini (2007), por sua vez, centrou sua análise em telejornais das cinco principais emissoras brasileiras, observando que notícias relacionadas à ciência estavam presentes em todos os dias analisados pela autora, em pelo menos um dos telejornais (sua amostra foi a programação de quatro semanas distribuídas entre os meses de maio de 2005 e maio de 2006).

O telejornal brasileiro de maior audiência - o Jornal Nacional da TV Globofoi o foco de algumas pesquisas, a exemplo de Ramalho, Polino e Massarani (2012) e Ramalho e colaboradores (2014). Nesses estudos, foi observado que 7,3\% dos conteúdos veiculados no período de abril de 2009 a março de 2010 se relacionavam à ciência. Já no Repórter Brasil, da emissora pública TV Brasil, o tempo diário médio no mesmo período de análise foi de 3,8\%, de acordo com o estudo de Reznik e colaboradores (2014). Algumas pesquisas já centraram a atenção em programas especiais voltados para a divulgação científica, como Globo Ciência (GUEDES, 1990; BARCA, 1999) e em publicidades (LEÓN, 2008; TORRES, 2013).

Esses estudos evidenciam que a ciência está presente na programação da TV em vários tipos de programação - do entretenimento aos informativos, das telenovelas e seriados às publicidades -, em diferentes horários, para os mais diversos públicos. Apesar disso, observamos que são reduzidas as pesquisas que trazem um panorama maior da programação da TV aberta, considerando os diferentes tipos de programações e categorias televisivas - e este é o objetivo deste artigo. ${ }^{1}$ Assim, apresentamos uma análise da programação da Rede Record, como representante das emissoras brasileiras, buscando analisar de que forma os conteúdos científicos são abordados ao longo da grade de programação televisiva diária.

\section{METODOLOGIA}

A escolha da Rede Record como objeto empírico de estudo é justificada por ser a mais antiga emissora de televisão ainda em atividade no Brasil e por ser a vice-líder de audiência no país entre os anos de 2007 e 2013 (MATTOS, 2010; MÍDIA DADOS, 2017b), período no qual a pesquisa que originou este artigo foi iniciada. Destaque-se que muitos estudos que relacionam ciência e TV no Brasil estão voltados para programação da TV Globo, a líder de audiência (ver, por exemplo, GUEDES, 1990; SIQUEIRA, 1998; GUERRA, 2004; RAMALHO, 2013) - de maneira que as demais emissoras acabam sendo pouco analisadas em razão da onipresença da emissora carioca. Além disso, a Record tem um perfil diferenciado, por ser dirigida por um grupo religioso (MATTOS, 2010) e ter um público da classe C e D maior que a TV Globo (FORATO, 2015).

A emissora foi criada em 1953 por Paulo Machado de Carvalho, na cidade de São Paulo, sendo a segunda a entrar no ar no Brasil, atrás apenas da pioneira TV Tupi, de Assis Chateaubriand (REDE RECORD, 1998; MAT'TOS, 2010). Teve seu apogeu na década de 1960, com a grande repercussão dos seus programas musicais e festivais de música que lançaram vários cantores e compositores importantes para a cultura brasileira, a exemplo de Roberto Carlos, Chico Buarque e Gilberto Gil (MATTOS, 2010). 
Entretanto, após uma série de incêndios em suas instalações no fim da década de 1960, a emissora entrou em decadência. Nos anos seguintes, passou a investir em telejornais, mas ainda enfrentou dificuldades. O bispo Edir Macedo, líder da Igreja Universal do Reino de Deus no Brasil, comprou a emissora em 1989 e a transformou em uma rede nacional (BOLAÑO, 2004; MAT'TOS, 2010). Sua programação começou a priorizar produtos populares, a exemplo do Ratinho Livre, que se tornou conhecido por apresentar testes de paternidade ao vivo (MATTOS, 2010).

A rede se estabilizou e se consolidou no mercado brasileiro nos últimos anos e, atualmente, possui sede em São Paulo e estúdios no Rio de Janeiro e em Brasília. Seu o sinal está disponível para $78,1 \%$ da população brasileira em todos os estados, incluindo o Distrito Federal, chegando a 4.351 municípios (MÍDIA DADOS, 2017a). Sua programação diária enfatiza os programas "policiais", como Cidade Alerta, Balanço Geral e o Câmera Record, e também investe na veiculação de produções estrangeiras, principalmente filmes e séries. A madrugada é reservada para programas religiosos da Igreja Universal.

Com objetivo de analisar a programação relacionada a temas científicos transmitidos pela emissora, realizamos um recorte de duas semanas construídas, em um total de 14 dias representativos de seis meses do ano de 2013 (junho a novembro). Tal recorte teve respaldo em estudo realizado por Whitelegg e colaboradores (2008), que analisou a programação televisiva no Reino Unido.

Para compor as semanas construídas, sorteamos aleatoriamente, no período considerado, duas segundas-feiras, duas terças-feiras, duas quartas-feiras, e assim sucessivamente, até termos duas vezes cada dia da semana. Ao todo, foram 336 horas gravadas e assistidas na íntegra nas seguintes datas:

Tabela I - Datas selecionadas para compor a amostra da pesquisa

\begin{tabular}{ccc}
\hline Domingo & 22 de setembro & 29 de setembro \\
\hline Segunda-feira & 19 de agosto & 16 de setembro \\
\hline Terça-feira & 18 de junho & 29 de outubro \\
\hline Quarta-feira & 18 de setembro & 13 de novembro \\
Quinta-feira & 12 de setembro & 24 de outubro \\
Sexta-feira & 04 de outubro & 29 de novembro \\
\hline Sábado & 31 de agosto & 14 de setembro \\
\hline
\end{tabular}

Nossa decisão de incluir a totalidade da programação ao longo das 24 horas do dia, no período analisado, foi um diferencial de nosso estudo, visto que, como mencionado anteriormente, na grande maioria dos estudos existentes, os pesquisadores analisaram programações televisivas específicas. Por outro lado, esta escolha também implicou em um desafio importante, pois tivemos como objetos empíricos uma ampla variedade de programas, incluindo peças publicitárias, reportagens jornalísticas, entrevistas em programas de variedades, cenas de telenovelas e seriados, para citar alguns exemplos. 
Para identificar as peças ${ }^{2}$ que analisaríamos em nosso estudo, definimos quatro critérios de seleção, que se basearam no protocolo da Rede Ibero-americana de Monitoramento e Capacitação em Jornalismo Científico (MASSARANI, RAMALHO, 2012), associado a Rondelli (2004) e Trench (2003). São eles:

- Menção direta à C\&T: citação das palavras ciência, tecnologia, cientistas, pesquisa, pesquisadores, instituições de pesquisa, universidades (desde que relacionadas à produção científica). Menção a métodos ou processos científicos, apresentação de resultados de pesquisas ou produtos desenvolvidos cientificamente, assim como assuntos relacionados à política de Ciência \& Tecnologia (C\&T) foram incluídos. Também foram incluídas as peças que apresentavam um cientista/pesquisador, desde que identificado dessa maneira.

- Menção a dados e termos científicos: Menção a dados ou termos atribuídos à comunidade científica ou a um determinado ramo do conhecimento, mesmo que não sejam proferidos por cientistas. Consideramos como dados científicos informações e/ou reflexões que não podem ser oriundas do senso comum, portanto tem origem no campo científico. Os termos científicos são caracterizados por palavras ou formações discursivas que não se encaixam no vocabulário do cotidiano, no senso comum, e são atribuídas à pesquisa científica.

- Presença de ilustração e/ ou animações relacionadas à ciência: inserção de peças que apresentam algum tipo de ilustração e / ou animação contendo informações científicas ou baseadas nelas, podendo ser uma explicação de um fato, um procedimento científico ou um exemplo da realidade.

- Material de divulgação científica: compreendem-se as programações televisivas com temáticas científicas voltadas para o público amplo e/ou leigo. Também são consideradas peças de divulgação da ciência aquelas programações que tratem de ações de popularização ou divulgação da ciência, como a Semana de Ciência e Tecnologia, olimpíadas e feiras de ciências, atividades dos museus de ciência, planetários e outros espaços científicos e culturais.

Posteriormente a essa seleção inicial, utilizamos um protocolo de análise visando extrair a maior quantidade de informações em cada peça analisada, sem deixar de incluir as diferenças características de cada categoria televisiva identificada. Mais uma vez o protocolo foi construído com base na ferramenta desenvolvida pela Rede Ibero-americana de Monitoramento e Capacitação em Jornalismo Científico (MASSARANI, RAMALHO, 2012) e é composto por sete eixos de análise: características gerais da peça (nome, emissora, data de veiculação, dia da semana de veiculação); temas abordados; tratamento (benefícios ou malefícios da ciência, contextualização, recomendações, etc.), características de formato e conteúdo televisivo; narrativa (enquadramento midiático); presença (ou não) de cientistas na peça; e os atores envolvidos. Neste artigo, trabalhamos mais detalhadamente as características gerais da peça, os temas abordados, o tratamento, as características de formato e conteúdo e a presença dos cientistas. 


\section{RESULTADOS}

Em nossa análise, identificamos 847 peças da programação da Rede Record que apresentaram, pelo menos, um dos critérios estabelecidos como prérequisitos para fazerem parte do nosso corpus de análise. A menção a dados e termos científicos esteve presente na maioria das peças identificadas (Gráfico 1), seguida pela presença das ilustrações relacionadas a questões científicas e à menção direta à ciência. Não registramos na emissora material algum caracterizado como de divulgação científica.

Gráfico 1 - Porcentagem de itens veiculados pela TV Record relacionados à ciência de acordo com os critérios no corpus ${ }^{3}$

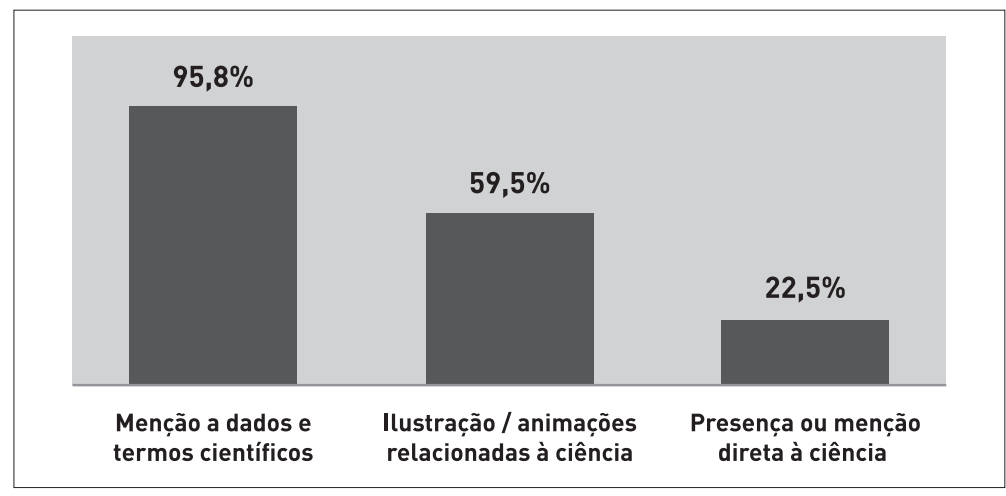

Somando todos os itens encontrados, chegamos a um total de 23 horas, 35 minutos e 9 segundos, o que representa cerca de 7,0\% de toda a programação da Record durante os 14 dias gravados e analisados. A grande maioria desse material era composto por peças de publicidade (Gráfico 2), de acordo com os conceitos de Aronchi (2004). ${ }^{4}$

Gráfico 2 - Porcentagem de itens relacionados à ciência na

TV Record distribuídos pelas categorias televisivas

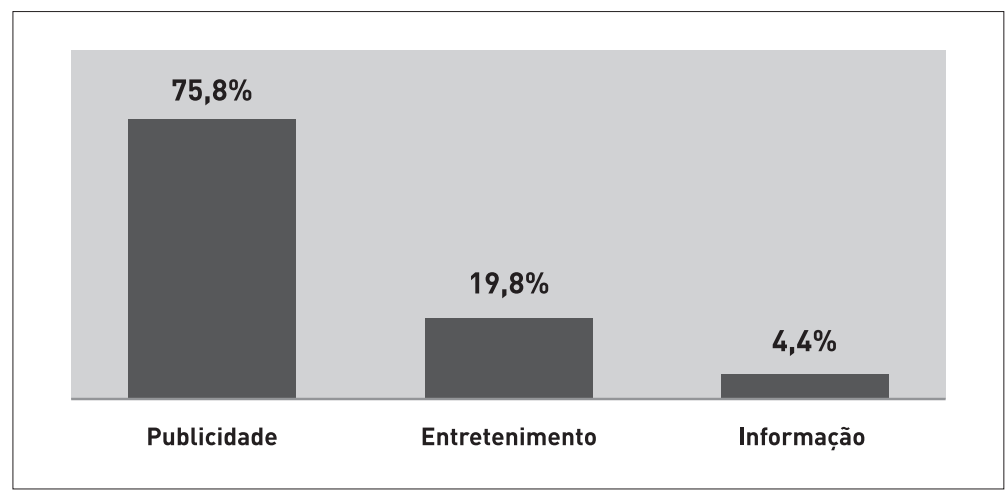


Do total, 75,8\% dos itens de ciência identificados na TV Record se inseriam na categoria publicidade. A maior parte dessas publicidades era de filmes comerciais ${ }^{5}$ (618 itens, 73,0\% do corpus), mas também verificamos materiais de merchandising dentro das programações fixas da emissora (22 itens, 2,6\%) e duas propagandas do gênero sorteio. Destaque-se que $97,3 \%$ das publicidades identificadas - a categoria televisiva mais representativa em nosso estudo - foram incorporadas ao corpus de análise por mencionar dados ou termos científicos, o critério mais recorrente em nossa análise.

Registramos conteúdos de ciência em materiais voltados para o entretenimento, entre os quais se destacaram os programas do gênero variedades (94 itens, 11,1\% de todo o corpus), a exemplo do Programa da Tarde e do Hoje em Dia. Nesses programas, os temas relacionados à ciência apareceram em quadros temáticos específicos, cujo assunto principal estava relacionado à saúde. Entre esses quadros podemos citar o "Além do peso", do Programa da Tarde, que acompanha o cotidiano de um grupo de pessoas que tentam perder peso sob a supervisão de nutricionistas, médicos e professores de educação física; e o "Você e o Doutor", do Hoje em Dia, que apresenta um caso clínico de um telespectador que ia ao programa para explicar sua situação e pedir um diagnóstico e dicas de tratamento para um médico presente no estúdio do programa.

Também na categoria de entretenimento, identificamos 20 peças $(2,4 \%)$ em um programa com um perfil interativo, em que os telespectadores participavam com perguntas por telefone ou vídeo. Trata-se do Fala que eu te escuto, transmitido no início da madrugada e apresentado por dois pastores da Igreja Universal, mas que não se enquadra dentro da programação religiosa da TV Record. A sua proposta é tratar de temas cotidianos e polêmicos e discuti-los com os telespectadores que se comunicam com os apresentadores ao vivo. Algumas vezes, registramos a presença de especialistas em determinados assuntos para gerar mais discussão. Entre os temas tratados pelo programa que abordaram questões científicas no período analisado podemos citar a experimentação com animais, a discussão sobre as manifestações populares que ocorreram no Brasil em junho de 2013 e as fobias humanas. Nesses casos, resultados de pesquisas, termos científicos e suas explicações estiveram presentes na fala dos especialistas, apresentadores e telespectadores - com usos diferenciados, de acordo com o grupo social ao qual pertenciam.

Ainda dentro da categoria de entretenimento, mas relacionada à teledramaturgia e materiais de ficção, encontramos itens de seriados de TV (43 itens, 5,0\% do total do corpus), desenhos animados (8 itens, 0,9\%) e filmes (2 itens, 0,2\%). Destacamos o seriado policial Criminal Science Investigation (CSI) em suas versões CSI New York e CSI Miami, produção norte-americana veiculada pela Record,de segunda a sexta-feira, por volta das $21 \mathrm{~h}$. Nesse seriado, especialistas forenses desvendam crimes a partir de análises clínicas e laboratoriais fazendo uso de métodos científicos com frequência, daí sua presença em nosso corpus de análise.

Observamos poucas programações voltadas para a informação (37 itens, $4,3 \%$ ), sendo que todas elas foram veiculadas em telejornais. Não identificamos item algum direcionado a programas educativos.

Das segundas-feiras aos sábados, a presença de programações diárias relacionadas à ciência foi em alguma medida constante (de 117 a 153 itens). Aos 
domingos, porém, registramos uma queda na abordagem dessas questões, com apenas 76 itens.

Ao longo do dia, observamos uma presença maior de peças durante a tarde (entre $12 \mathrm{~h} 01 \mathrm{~s} \mathrm{e} 18 \mathrm{~h})$ e a noite (18h01s e 00h). À tarde a programação praticamente se resume aos programas de variedades; à noite são veiculadas as séries policiais, como CSI citada acima, e o principal jornal da emissora, o Jornal da Record.

Ciências Biológicas foi a área do conhecimento mais abordada nas peças relacionadas à ciência, estando presente em 55,4\% delas (ver Gráfico 3). Em seguida, observamos as programações relacionadas à Medicina e Saúde, que representaram 36,4\% do material. As Ciências Sociais Aplicadas estavam presentes em 4,5\% das peças e as Ciências Humanas, em 1,5\%. Já as demais áreas do conhecimento, como Ciências Exatas, Agrárias, Ambientais, Linguística e as Engenharias ou assuntos de C\&T como um todo não atingiram mais de 1\% do corpus.

Gráfico 3 - Porcentagem de itens relacionados à ciência na TV

Record distribuídos pelas áreas do conhecimento mais frequentes

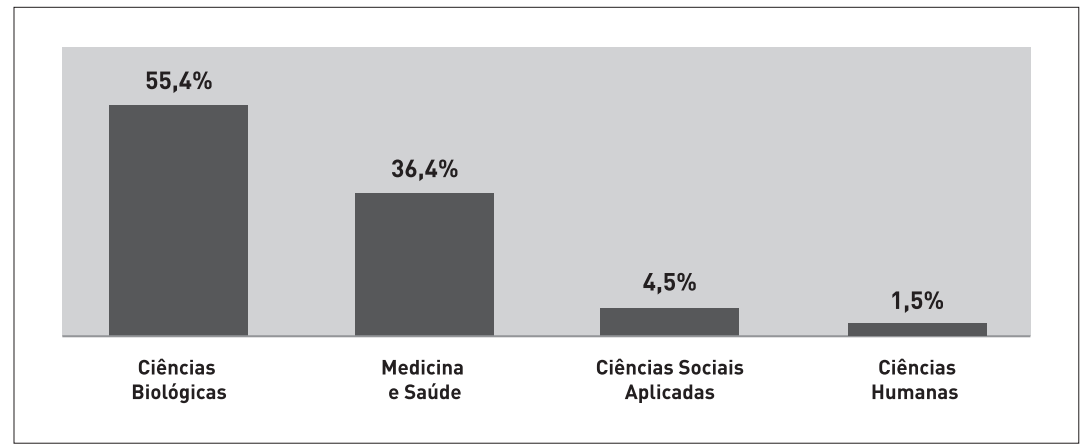

Essa concentração de peças envolvendo Ciências Biológicas e Medicina e Saúde se expressa nas temáticas registradas na programação da Record. Houve predominância de assuntos voltados para questões estéticas, como cosméticos, hidratantes, cicatrizantes e produtos para os cabelos, principalmente nas publicidades, que foram as peças mais comuns em nosso material. Tais temáticas estavam relacionadas às Ciências Biológicas, principalmente, assim como as cenas de laboratório da série CSI. Em contrapartida, as temáticas relacionadas à saúde foram abordadas em programações que tratavam de remédios, emagrecimento e suplementos alimentares.

Em grande medida, os conteúdos expressaram o lado positivo da atividade científica: os benefícios proporcionados pela ciência foram destacados em 81,2\% do corpus e suas promessas futuras, em 66,5\%. Já os riscos em potencial e os malefícios causados pela ciência estiveram em apenas $6,4 \%$ e 4,1\%, respectivamente, do nosso material.

\subsection{Presença do cientista}

Dos 847 itens de ciência identificados na Rede Record, somente 30 apresentaram a figura do cientista, o que representa $3,5 \%$ de todos os itens 
identificados na emissora. Considerando que uma mesma peça poderia incluir mais de um cientista, identificamos no total 38 cientistas: 33 homens e 5 mulheres.

A Imagem 1 mostra o perfil padrão dos homens cientistas da TV Record: homens vestidos de jalecos (84,8\% dos casos registrados) e trabalhando em laboratórios (66,7\%). Muitos deles ainda apareceram fazendo uso de vidrarias de laboratório $(45,4 \%)$ e usando óculos $(33,6 \%)$.

Quase metade deles participou de programações relacionadas à área de Medicina e Saúde (45,5\%); estiveram presentes também em peças sobre Ciências Exatas e da Terra e Ciências Biológicas (24,2\% 21,2\% respectivamente). As peças de entretenimento foram as que mais apresentaram homens cientistas na TV Record (51,5\% dos homens cientistas), seguidas pelas de publicidades $(39,4 \%)-$ destacadas na Imagem 1. Mas se trata de número reduzido de cientistas.

Imagem 1 - Exemplos de cientistas homens em publicidades veiculadas pela TV Record

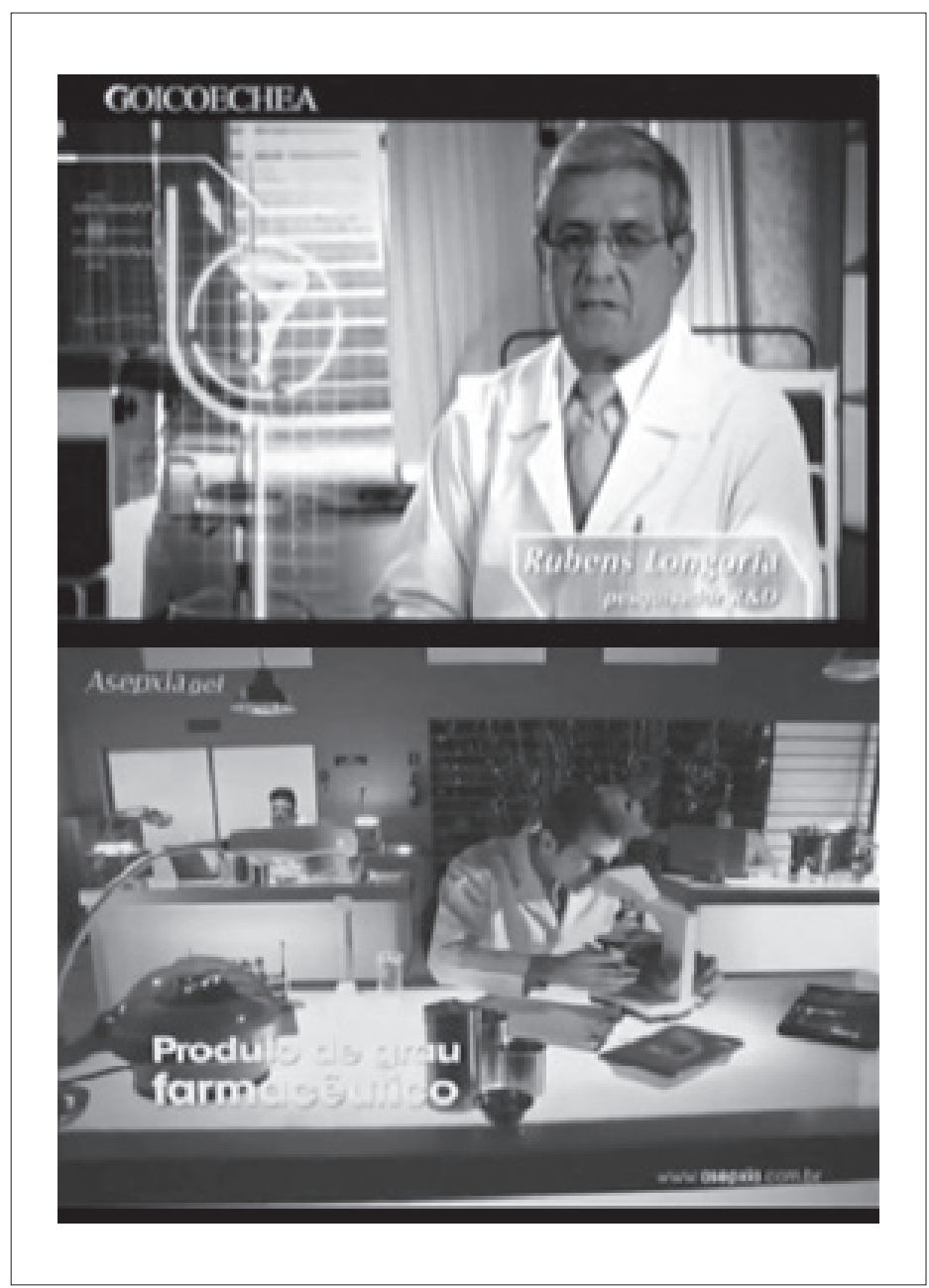


Na Imagem 1, vemos, à esquerda, a propaganda de um hidratante em que o pesquisador faz recomendações ao telespectador, mostrando as vantagens do produto baseado em seus estudos. Na figura à direita, o produto ofertado é um remédio para controle de acne e são apresentadas imagens do laboratório no qual teria sido desenvolvido tal remédio - incluindo alguns pesquisadores como o representado na imagem.

Imagem 2 - Exemplo de cientista homem em desenhos animados veiculados pela TV Record

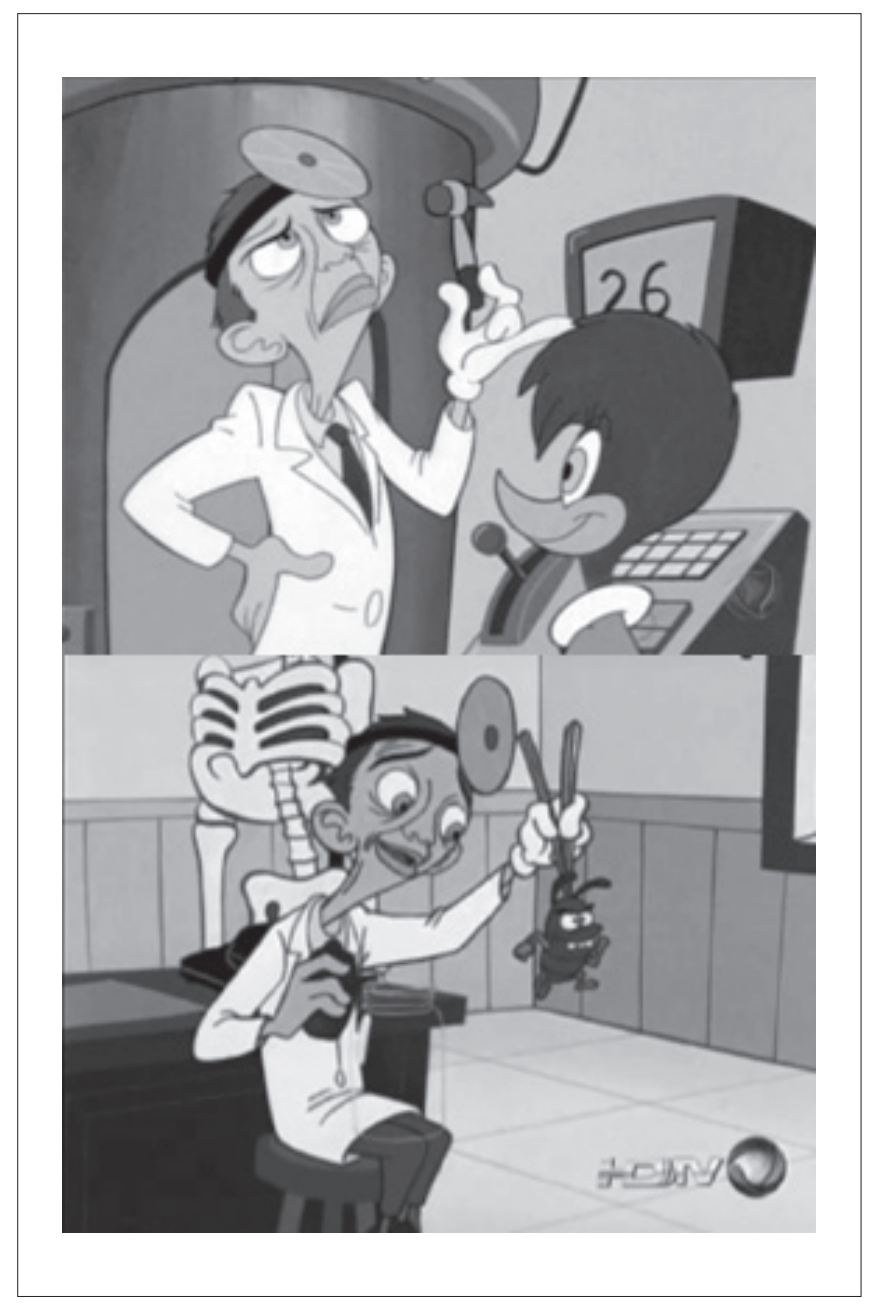

Nos desenhos animados, também se mantém a representação do cientista como um homem, branco, de jaleco, em um laboratório. No entanto, nos desenhos, há ênfase no perfil de "cientista maluco", descabelado, atrapalhado e gênio. Este é o caso de Pica Pau, transmitido nos finais de semana pela TV Record (Imagem 2). Na imagem à esquerda, o cientista estava tentando fazer um clone da sobrinha do Pica Pau, Winnie, a personagem principal do episódio; à direita, o mesmo personagem 
cientista desenvolveu um cupim geneticamente modificado para degradar mais madeira que um cupim em seu estado natural, ajudando o Pica Pau nessa atividade. As duas experiências não resultam da forma que o pesquisador previu e ele tenta contornar a situação de várias formas.

Identificamos apenas cinco mulheres cientistas em toda a programação analisada. Três delas eram brasileiras e outras duas estrangeiras. Quatro delas estavam em laboratórios, três vestiam jalecos e duas trabalharam com vidrarias.

Três pesquisadoras foram mostradas em programação sobre Medicina e Saúde; outra delas foi associada a Ciências Humanas e, a última, a Ciências Biológicas. Duas cientistas participaram de programas de entretenimento e outras três em peças informativas (ver Imagem 3).

Imagem 3 - Exemplos de cientistas mulheres na TV Record

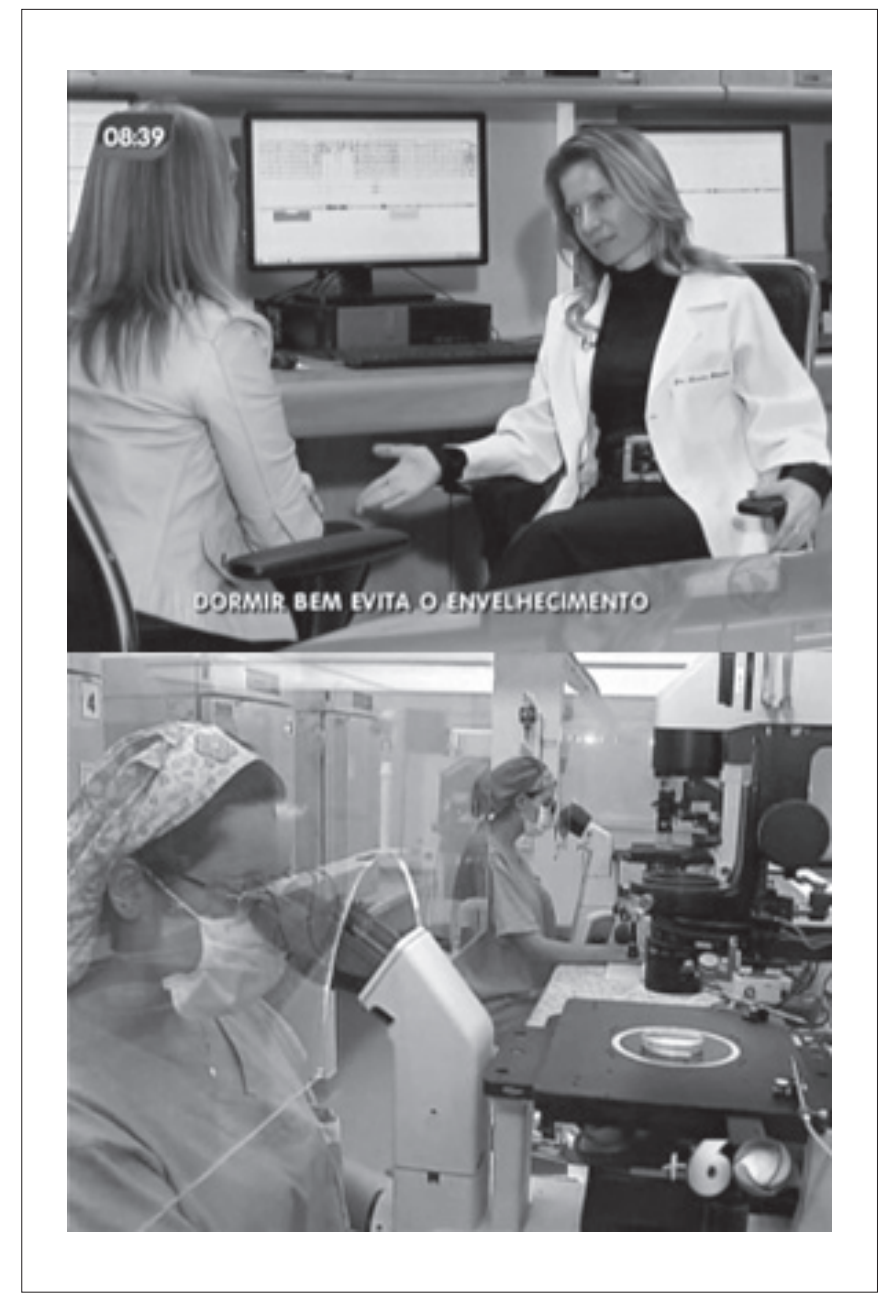


$\mathrm{Na}$ figura à esquerda, a pesquisadora concede entrevista ao programa Balanço Geral RJ sobre os benefícios do sono para evitar o envelhecimento precoce da pele, em especial das mulheres. À direita estão duas pesquisadoras de uma equipe de cientistas norte-americanos que está desenvolvendo uma possível vacina contra o HIV, em notícia veiculada pelo telejornal Fala Brasil.

Nas imagens apresentadas, é possível observar que as mulheres se assemelham em alguns aspectos ao perfil do homem cientista. Elas estavam em laboratórios e vestidas de jaleco, contudo, nossos dados sobre elas são muitos reduzidos para fazermos alguma inferência sobre um padrão das mulheres cientistas na TV Record.

\section{DISCUSSÃO E CONSIDERAÇÕES FINAIS}

Ao longo das 336 horas assistidas na TV Record, identificamos que $7,0 \%$ da programação estavam relacionados à ciência, mostrando que a temática, em alguma medida, faz parte dessa programação diária, em distintos gêneros televisivos. No entanto, a temática não é tratada de maneira regular ao longo do dia, com destaque nos horários da tarde e da noite.

Esse resultado ganha relevância tendo em vista a importância da TV como fonte de informações sobre assuntos gerais para a população (REIMÃO, 2000) e, em particular, sobre temas de ciência no Brasil (MCTI, CGEE, 2015) e em outros países latino-americanos (OCyT, 2014; REDCYTEC, CONARE, 2012; MINCYT, 2014; CONICY'T, 2016). Além disso, o perfil de público da emissora, marcado por grupos com menor poder aquisitivo (FORATO, 2015) e, possivelmente, menor instrução, nos leva a refletir sobre o papel da programação televisiva na construção de conceitos e estereótipos sobre a ciência por esses telespectadores.

Para Orozco-Gómez (2005), a TV é uma instituição social produtora de significados, o que lhe confere um poder legitimador junto aos seus telespectadores. A "produção de notícias" e o apelo "emotivo" da televisão são fatores que chamam atenção de quem assiste TV e tornam a sua programação mais real: "à TV basta colocar seu telespectador frente à tela para colocá-lo (aparentemente) frente à realidade" (OROZCO-GÓMEZ, 2005, p. 30).

Em nosso estudo, percebemos que as publicidades - gênero televisivo que mais abordou questões científicas - utilizaram o discurso científico por meio de expressões como "cientificamente provado" e a imagens de cientistas como legitimador dos produtos que pretende vender, potencializando ainda mais essa sensação de "realidade" da qual fala Orozco-Gómez (2005).

Conforme Torres (2013) destaca em seu estudo sobre publicidades televisivas na Colômbia, a noção de "compreensão de ciência" nessas peças se reduz à concessão de algumas informações sobre as características ou funcionamento do produto, sem o objetivo de tratar sobre os assuntos científicos em si nessas peças. As informações ofertadas nesse tipo de programação visam o convencimento dos telespectadores para o consumo do produto, ou seja, a legitimidade social da ciência é utilizada no discurso da venda do produto, buscando respaldar a informação de que as características do produto teriam respaldo científico e, portanto, seriam "reais". 
Vale mencionar que as peças identificadas da categoria informação foram veiculadas nos telejornais da emissora, mas foram raras $(4,4 \%)$, enquanto que programações voltadas para a divulgação científica não foram encontradas no nosso corpus.

A segunda categoria televisiva mais frequente em nosso material foram aspeças de entretenimento. Nela, encontramos programas de variedades, cenas de filmes, desenhos animados e séries que desenvolviam questões relacionadas à ciência. No caso dos desenhos, em sintonia com estudos anteriores (por exemplo, ROSA e colaboradores, 2005; SIQUEIRA, 2006; MESQUITA e SOARES, 2008), observamos a representação estereotipada do cientista, caracterizada pela figura masculina, vestida de jaleco e que trabalha em um laboratório. Essa imagem do profissional da ciência já foi identificada em muitos estudos desde a análise de Mead e Metraux (1957), seja em pesquisas com crianças (CHAMBERS, 1983; STEINKE et al, 2007; WHITELEGG et al., 2008) ou com jovens e adultos (RAMALHO, 2013; SOARES, SCALFI, 2014). Steinke e colaboradores (2007) mostram, inclusive, uma relação entre imagens dos cientistas divulgadas na mídia e as concepções do público, evidenciando a necessidade de se estar alerta para o tema, no âmbito educacional.

Ressaltamos a presença do seriado CSI em nosso corpus. A série apresenta resoluções de crimes policiais com a ajuda de uma equipe de especialistas forenses que se utilizam de vários métodos, práticas e exames científicos. Tal programa vem fazendo bastante sucesso internacionalmente, causando o chamado "efeito CSI", caracterizado por uma apropriação de certos procedimentos científicos por parte de seus telespectadores (LEY, JANKOWSKI, BREWER, 2012; THOMAS, 2006). No Brasil, não é possível afirmar que a série terá efeitos similares ao que ocorre nos Estados Unidos. Entretanto, ao enfatizar as questões científicas para resolver um crime, a série tem potencial de estimular as audiências brasileiras a pensar sobre os processos da ciência. Essa programação é veiculada nas noites de segunda à sextafeira, horário no qual verificamos a presença de assuntos científicos de maneira recorrente em razão do seriado. Vale mencionar que a programação da TV Record prioriza os programas voltados para as questões policiais em si, que exploram crimes de âmbito local e nacional e são reconhecidos por seus apresentadores "populares".

A menção a dados e termos científicos foi recorrente em todos os tipos de programações, assim como a presença de animações para explicar uma informação ou exemplificar cientificamente algum processo ou método.No entanto, nossos dados mostram a reduzida veiculação da imagem dos cientistas, sugerindo que a emissora não considerou necessária a presença deste ator social como fonte legitimadora das informações. Quando os cientistas estiveram presentes, seguiram o estereótipo de cientista homem, de jaleco, associado a laboratórios.

Dados da enquete de percepção pública sobre a ciência e a tecnologia no Brasil mostram que a grande maioria dos entrevistados $(93,0 \%)$ não soube mencionar um cientista brasileiro (MCTI, CGEE, 2015). Nesse sentido, é importante que a televisão dê espaço para os pesquisadores do país, possibilitando que a população tenha maior conhecimento das atividades científicas realizadas no país - o que não foi observado em nosso estudo, já que a grande maioria dos cientistas era estrangeira. 
As mulheres tiveram presença ínfima na programação analisada: apenas cinco, entre 38 cientistas, nas 336 horas assistidas. Isso contrasta com dados do CNPq, que mostram uma tendência ao equilíbrio de gêneros na comunidade científica brasileira nos últimos anos (CNPq, 2010).Seria interessante, portanto, realizar uma análise mais aprofundada em busca de razões e padrões para essa baixa presença das mulheres em carreiras científicas na televisão.

Assim, buscamos fazer um panorama geral da presença da ciência na TV, tendo como foco uma das emissoras de maior audiência do Brasil, a TV Record. Nosso objetivo foi identificar e caracterizar a inserção dessa temática na TV, por ser o principal meio de comunicação de massa do Brasil (IBGE, 2013),que tem o potencial de contribuir na formação educacional da população (REIS, 2002; GARCÍA-CANCLINI, 2008). Ademais, a TV como instituição social tem uma presença importante na construção e no reconhecimento do real entre aqueles que a assistem (OROZCO-GÓMEZ, 2005), para além do papel de preenchimento de horários de lazer das pessoas (JACKS, MENEZES, PIEDRAS, 2008).

Em particular, concentramo-nos na TV Record, caracterizada por ter uma programação com temáticas religiosas e policiais principalmente, mas que também investe em produtos "enlatados" estrangeiros, como filmes e seriados. (MATTOS, 2010; ROCHA, 1999). Nossos dados mostram que a ciência está presente na programação da emissora em vários horários ao longo do dia e em diversos programas ao longo da semana. Nesse sentido, esperamos contribuir com a reflexão acerca das informações sobre ciência que público brasileiro está recebendo tais informações de ciência, que lhe chegam de variadas maneiras na programação diária de uma emissora com um perfil tão singular e que alcança altos índices de audiência.

\section{REFERÊNCIAS}

ALBERGUINI, A. A ciência nos telejornais brasileiros (o papel educativo e a compreensão pública das matérias de C\&T). Tese (Doutorado em Comunicação Social) - Universidade Metodista de São Paulo (UMESP), São Paulo, 2007.

ARONCHI, J. Gêneros e formatos na televisão brasileira. São Paulo: Summus, 2004.

BARCA, L. Iguarias à Hora do Jantar: a Presença de Ciência e Tecnologia nos Telejornais Diários. Tese (Doutorado em Educação, Gestão e Difusão em Ciências) - Universidade Federal do Rio de Janeiro (UFRJ), Rio de Janeiro, 2004.

BARCA, L. Ciência e comunicação na TV comercial: 14 anos do Programa Globo Ciência. Comunicação \& Educação. n. 15, v. 81-86, mai/ago 1999.

BOLAÑO, C. Mercado brasileiro de televisão. $2^{\mathrm{a}}$ ed. São Cristóvão (SE): Universidade Federal de Sergipe; São Paulo: EDUC, 2004.

CHAMBERS, D. Stereotypic images of the scientist: the draw-a-scientist test. Science Education, v. 67, n. 2, p 255-265, 1983.

COLE, S.; DIOSO-VILLA, R. Investigating the 'csi effect' effect: media and litigation crisis in criminal law. Stanford Junior University: Stanford Law Review, 2009.

COMISIÓN NACIONAL DE INVESTIGACIÓN CIENTÍFICA Y TECNOLÓGICA (CONACYT). Encuesta nacional de percepción social de la ciencia y la tecnología en Chile 2016. Santiago: Departamento de Estudios y Gestión Estratégica, 2016. Disponível em: <http:// 
www.conicyt.cl/blog/2016/07/conicyt-presenta-resultados-de-la-encuesta-nacional-de-percepcionsocial-de-la-ciencia-y-la-tecnologia-en-chile/>. Acesso em: 21 set. 2017.

CONSELHO NACIONAL DE DESENVOLVIMENTO CIENTÍFICO E TECNOLÓGICO.

Estatísticas. 2010.Disponível em: <http://www.memoria.cnpq.br/estatisticas/bolsas/graficos. htm>. Acesso em: 04 mai. 2015.

EUROPEAN COMMISSION. Special Eurobarometer on scientific research in the media.2007. Disponível em: < http://ec.europa.eu/public_opinion/archives/ebs/ebs_282_en.pdf.> Acesso em: 9 mai. 2012.

FORATO, T. Globo e Record têm mais público A/B; SBT ganha entre os jovens. Na telinha. São Paulo, 22 set. 2015. Disponível em: < http://natelinha.ne10.uol.com.br/noticias/2015/07/22/globoe-record-tem-mais-publico-ab-sbt-ganha-entre-os-jovens-90952.php>. Acesso em: 1 set. 2015.

GARCÍA-CANCLINI, N. Latino-americanos à procura de um lugar neste século. São Paulo: Iluminuras, 2008.

GUEDES, A. Globo Ciência: inventário e análise do arquivo de cartas recebidas dos telespectadores em 1988. Dissertação (mestrado em Ciência da Informação) - Instituto Brasileiro de Informação em Ciência e Tecnologia (IBICT) - Universidade Federal do Rio de Janeiro, Rio de Janeiro, 1990.

GUERRA, R. O Discurso Sobre a Ciência nas Telenovelas O Clone e Barriga de Aluguel. Dissertação (Mestrado em Comunicação) - Universidade Federal de Pernambuco (UFPE), Recife, 2004. INSTITUTO BRASILEIRO DE GEOGRAFIA E ESTATÍSTICA (IBGE). Acesso à internet è̀ televisão e posse de telefone móvel celular para uso pessoal: 2015. Coordenação de Trabalho e Rendimento. Rio de Janeiro: IBGE, 2016.

JACKS, N.; MENEZES, D.; PIEDRAS, E. Meios e audiências: a emergência dos estudos de recepção no Brasil. Porto Alegre: Sulina, 2008.

LEÓN, B. Science related information in European television: a study of prime-time news. Public Understanding of Science, v. 17, n. 4, p. 443-460, 2008.

LEY, B.; JANKOWSKI, N.; BREWER, P. Investigating CSI: Portrayals of DNA testing on a forensic crime show and their potential effects. Public Understanding of Science. v. 21, n. 1, p. 51-67, 2012.

MASSARANI, L.; MOREIRA, I. O clone. Public Understanding of Science, Londres, v. 11, n.2, p. 207-208, 2002.

MASSARANI, L.; RAMALHO, Marina. Monitoramento e capacitação em jornalismo científico: a experiência de uma rede ibero-americana. Rio de Janeiro: Museu da Vida/Casa de Oswaldo Cruz/Fiocruz: Centro Internacional de Estudios Superiores de Comunicación para América Latina (Ciespal), 2012.

MATTOS, Sérgio. História da televisão brasileira: uma visão econômica, social e política. Petrópolis: Editora Vozes, $5^{\text {a }}$ ed., 2010.

MEAD, M.; METRAUX, R. Image of the Scientist among High-School Students: a pilot study. Science, n. 30, v. 126, p. 384-390, ago, 1957.

MEDEIROS, F. et al. Ciência e tecnologia em um programa de infotainment: uma análise de conteúdo da cobertura do Fantástico. Intercom: revista brasileira de ciências da comunicação, v. 36, p. 127-147, 2013.

MESQUITA, N.; SOARES, M. Visões de ciência em desenhos animados: uma alternativa para o debate sobre a construção do conhecimento científico em sala de aula. Ciência \& Educação, v. 14, n. 3, p. 417-29, 2008.

MÍDIA DADOS BRASIL. Televisão Aberta: Cobertura geográfica de TV. 2017a. Disponível em: <https://dados.media/\#!/view/CATEGORY/TELEVISION/MDB_TVA_COBERTURA_ GEOGRAFICA_TV>. Acesso em: 21 set. 2017.

MÍDIA DADOS BRASIL. Televisão Aberta: Evolução do share nacional das redes.2017b. Disponível em: <https://dados.media/\#!/view/CATEGORY/TELEVISION/MDB_TVA_ EVOLUCAO_SHARE_NACIONAL_REDES>. Acesso em: 21 set. 2017. 
MINISTÉRIO DA CIÊNCIA, TECNOLOGIA E INOVAÇÃO. CENTRO DE GESTÃO E ESTUdos estratégiCOS (MCTI, CGEE). Percepção pública da C\&T no Brasil 2015. Brasília. 2015. Disponível em: < http://pt.slideshare.net/MCTI/percepo-pblica-da-ct-2015-cgee>. Acesso em: 15 ago. 2015.

MINISTERIO DE CIENCIA, TECNOLOGÍA E INNOVACIÓN PRODUCTIVA (MINCYT). La percepción de los argentinos sobre la investigación científica en el país. Tercera Encuesta Nacional (2012). Ciudad Autónoma de Buenos Aires, Ministerio de Ciencia, Tecnología e Innovación Productiva, 2014.

NATIONAL SCIENCE FOUNDATION. Science and technology: public attitudes and understanding. Science and Engineering Indicators 2012. 2012. Disponível em: http:/ /www.nsf. gov/statistics/seind12/c7/c7h.htm. Acesso em: 19 abr. 2013.

OBSERVATORIO COLOMBIANO DE CIENCIA Y TECNOLGÍA (OCyT). Percepciones de las ciencias y las tecnologías en Colombia. Resultados de la III Encuesta Nacional de Percepción Pública de la Ciencia y laTecnología. Editoras Sandra Daza-Caicedo, Marcela Lozano-Borda. Bogotá: Observatorio Colombiano de Ciencia y Tecnología, 2014. Disponível em: < http://ocyt.org.co/ proyectos-y-productos/percepciones-de-las-ciencias-y-las-tecnologias-en-colombia-resultados-de-laiii-encuesta-nacional-de-percepcion-publica-de-la-ciencia-y-la-tecnologia >. Acesso em: 21 set. 2017.

OROZCO-GÓMEZ, G. O telespectador frente à televisão: uma exploração do processo de recepção televisiva. Comunicare, v. 5, n. 1, 2005.

RAMALHO, M. A ciência no Jornal Nacional e na Percepção do Público. Tese (Doutorado em Química Biológica) - Universidade Federal do Rio de Janeiro, Rio de Janeiro, 2013.

RAMALHO, M.; POLINO, C.; MASSARANI, L. Do laboratório para o horário nobre: a cobertura de ciência no principal telejornal brasileiro. Journal of Science Communication, v. 11, p. 1-10, 2012.

RED DE COMUNICACIÓN DE LA CIENCIA, LA TECNOLOGÍA Y LA INNOVACIÓN (REDCYTEC), CONSEJO NACONAL DE RECTORES (CONARE). Percepción social de la ciencia y la tecnología en Costa Rica: Um estúdio del IDESPO para la Subcomisión Red de Comunicación de la Ciencia, la Tecnología y la Innovación del Consejo Nacional de Rectores [multimedia] / Red Cy Tec ; María de los Ángeles Carrillo Delgado, Juan Carlos Bermúdez Mora, Guiselle Bustos Mora; editado por Greivin Rodríguez Calderón. - 1ª ed. - San José, C.R.: Consejo Nacional de Rectores, 2012.

REDE RECORD. Rede Record: 45 anos de história. São Paulo: Antonio Bellini Editora e Design, 1998. REIMÃO, S. A televisão no Brasil - ontem e hoje. In: REIMAO, S. Televisão na América Latina: 7 estudos. São Bernardo do Campo: Universidade Metodista de São Paulo, p. 7-10, 2000.

REIS, J. Ponto de vista: José Reis. In: MASSARANI, L.; MOREIRA, I.; BRITO, F. Ciência e público: caminhos da divulgação científica no Brasil. Rio de Janeiro: Casa da Ciência - Centro Cultural de Ciência e Tecnologia/Universidade Federal do Rio de Janeiro. Fórum de Ciência e Cultura, 2002, p. 73-78. Disponível em: <http://www.casadaciencia.ufrj.br/Publicacoes/terraincognita/ cienciaepublico/livro_completo.pdf $>$. Acesso em: 1 dez. 2012.

REZNIK, G.; MASSARANI, L.; RAMALHO, M.; AMORIM, L. Ciência na televisão pública: uma análise do telejornal Repórter Brasil. Alexandria (UFSC), v. 7, p. 157-178, 2014.

ROCHA, P. Televisão e religião no mercado global: TV Record e Rede Vida. In: REIMÃO, S. Televisão na América Latina: 7 estudos. São Bernardo do Campo: Universidade Metodista de São Paulo, p. 117-135, 2000.

RONDELLI, D. A ciência no picadeiro: Uma análise das reportagens sobre ciência no programa Fantástico. Dissertação (Mestrado em Comunicação Social) - Universidade Metodista de São Paulo (UMESP), São Paulo, 2004.

ROSA, M. et al. Os cientistas nos desenhos animados e os olhares das crianças. In: V ENCONTRO NACIONAL DE PESQUISA EM EDUCAÇÃO EM CIÊNCIAS, 2005, Bauru (SP). Anais..., 2005. 
SIQUEIRA, D. O cientista na animação televisiva: discurso, poder e representações sociais. Em questão, Porto Alegre, v. 2, n. 1, p. 131-148, jan/jun, 2006.

SIQUEIRA, D. Ciência na televisão: mito ritual e espetáculo. Dissertação (Mestrado em Informação) - Universidade Federal do Rio de Janeiro (UFRJ), Rio de Janeiro, 1998.

SOARES, G.; SCALFI, G. Adolescentes e o imaginário sobre cientistas: análise do teste "Desenhe um cientista" (DAST) aplicado com alunos do $2^{\circ}$ ano do Ensino Médio. In: CONGRESO IBEROAMERICANO DE CIENCIA, TECNOLOGÍA, INNOVACIÓN Y EDUCACIÓN, 2014, Buenos Aires (Argentina). Anais. 2014.

STEINKE, J. et al. Assessing media influences on middle school-aged children's perceptions of women in science using the draw-ascientist text (DAST). Science Communication, v. 29, p. 35-64, 2007.

THOMAS, A. The CSI Effect: Fact or Fiction. The Yale Law Journal Pocket, parte 115:70, p. 70-72, 2006.

TORRES, H. Uso de la ciencia en la publicidade televisiva colombiana. Un estudio exploratorio sobre las representaciones de la ciencia em la televison. Universitas humanistica, n. 75, p. 447-475, janeiro-junho 2013.

TRENCH, B. Media Studies Module. The European Network of Science Communication Teachers. 2003.

WHITELEGG, E. et al. (In)visible Witnesses: Investigating gendered representations of scientists, technologists, engineers and mathematicians on UK children's television. UK Resource Centre for Women in Science, Engineering and Technology, Bradford, UK, 2008.

\section{NOTAS}

${ }^{1}$ Este estudo integra um projeto mais amplo, apoiado pelo CNPq e pela Faperj, realizado em colaboração com quatro instituições brasileiras (Fundação Oswaldo Cruz, Universidade de São Paulo e Universidades Federais do Pará e de Minas Gerais). Neste artigo, apresentamos um recorte referente aos dados coletados no Rio de Janeiro e relacionados à programação da TV Record.

${ }^{2}$ Por peça, consideramos: reportagens jornalísticas; entrevistas; quadros temáticos de programas; cenas de telenovelas, séries, minisséries, filmes, desenhos; peças publicitárias; e merchandising em programas de variedades. Cada peça incluída deveria apresentar, pelo menos, um desses critérios.

${ }^{3}$ A soma das porcentagens supera $100 \%$ porque cada peça poderia apresentar mais de um critério de inclusão no corpus.

${ }^{4}$ Aronchi (2004) identifica cinco categorias televisivas: entretenimento, informação, educação, publicidade e outros (programações especiais, religiosos e eventos).

${ }^{5}$ Filmes comerciais é a nomenclatura utilizada por Aronchi (2004) para identificar as propagandas comerciais veiculadas nos intervalos dos programas televisivos.

\section{Submetido em 01/09/2015}

Aprovado em 30/09/2017

\section{Contato:}

Núcleo de Estudos da Divulgação Científica / Museu da Vida

Casa de Oswaldo Cruz / Fundação Oswaldo Cruz

Av. Brasil, 4.365

CEP 21.040-900 - Manguinhos, Rio de Janeiro, RJ - Brasil 